\title{
Development of a window correlation matching method for improved radar rainfall estimation
}

\author{
T. Piman, M. S. Babel, A. Das Gupta, and S. Weesakul \\ Water Engineering and Management, Asian Institute of Technology, Pathumthani, Thailand \\ Received: 13 December 2006 - Published in Hydrol. Earth Syst. Sci. Discuss.: 1 March 2007 \\ Revised: 14 May 2007 - Accepted: 23 May 2007 - Published: 7 June 2007
}

\begin{abstract}
The present study develops a method called window correlation matching method (WCMM) to reduce collocation and timing errors in matching pairs of radar measured reflectivity, $Z_{e}$, and gauge measured rainfall intensity, $R$, for improving the accuracy of the estimation of $Z_{e}-R$ relationships. This method was compared with the traditional matching method (TMM), the probability matching method (PMM) and the window probability matching method (WPMM). The calibrated relationship $Z_{e}=18.05 R^{1.45}$ obtained from $7 \times 7 \mathrm{~km}$ of space window and both present and 5 min previous time of radar observation for time window (S77T5) produces the best results for radar rainfall estimates for orographic rain over the Mae Chaem Watershed in the north of Thailand. The comparison shows that the $Z_{e}-R$ relationship obtained from WCMM provide more accuracy in radar rainfall estimates as compared with the other three methods. The $Z_{e}-R$ relationships estimated using TMM and PMM provide large overestimation and underestimation, respectively, of mean areal rainfall whereas WPMM slightly underestimated the mean areal rainfall. Based on the overall results, it can be concluded that WCMM can reduce collocation and timing errors in $Z_{e}-R$ pairs matching and improve the estimation of $Z_{e}-R$ relationships for radar rainfall. WCMM is therefore a promising method for improved radar-measured rainfall, which is an important input for hydrological and environmental modeling and water resources management.
\end{abstract}

\section{Introduction}

Rainfall is measured based on three sensors- rain gauge, weather radar and satellite. Rain gauges are traditionally used for measuring rainfall at ground level. Gauge-measured

Correspondence to: T. Piman

(st100803@ait.ac.th) rainfall is often regarded as the true or reference rainfall. However, inaccurate rainfall estimates based on rain gauges are due to inadequate spatial coverage or configuration and inadequate gauge density especially in mountainous regions (Borga, 2002). Satellites are an attractive alternative to observe rainfall at a global scale from space with large spatial and temporal resolution. However, it is difficult to apply satellite rainfall in small scale basins (less than $10^{3} \mathrm{~km}^{2}$ ) and in real time operation (Linsley et al., 1988; Collier, 1996). In addition, the accuracy of satellite rainfall estimation decreases when the time scale is reduced (i.e., from monthly to daily to sub-daily). Weather radar overcomes some of the disadvantages associated with rain gauges and satellites as it provides a rain field with high spatial and temporal resolution and large areal coverage. Also, it measures rainfall closer to the ground level than the satellite. Application of radar measured rainfall in hydrological and environmental modeling, including real-time hydrological forecasting, has become an active area of research by hydrologists (Collinge and Kirby, 1987; Bell and Moore, 1998; Sun et al., 2000; Vieux, 2003).

In measuring rainfall by radar, $Z-R$ relationships are widely used to convert radar measured reflectivity to rainfall intensity, hence the accuracy of the estimation of $Z-R$ relationship is important (Rosenfeld et al., 1993; Collier, 1996; Atlas et al., 1997). The true radar reflectivity $(Z)$, which can be measured by distrometer, is determined based on the drop size distribution (DSD) of rainfall and is related to rainfall intensity $(R)$ to estimate the true $Z-R$ relationship (Atlas, 1964; Battan, 1973). However, non-availability of raindrop size distribution information restricts the determination of the true $Z-R$ relationship based on DSD.

Calheiros and Zawadzki (1987) and Rosenfeld et al. (1990) applied a regression analysis technique to determine the relationship of synchronous datasets between measured rainfall intensity by rain gauge and measured or effective reflectivity by weather surveillance $\operatorname{radar}\left(Z_{e}\right)$ at the pixel over the rain gauge (defined as the traditional matching

Published by Copernicus GmbH on behalf of the European Geosciences Union. 
method, TMM, in this paper). However, in reality perfect synchronization between $Z_{e}$ and $R$ is unachievable, except at the closest range and nearest to the ground. The nonsynchronous $Z_{e}-R$ pairs are due to: 1) the large discrepancy between the sample volume of the rain gauge and the radar, 2) timing and geometric mismatches, and 3) the large variability of the $Z-R$ relationships mainly due to differences of rainfall characteristics, locations and times (Joss et al., 1970; Battan, 1973; Chumchean, 2004). These problems reduce the accuracy of $Z_{e}-R$ conversion for radar rainfall estimates.

To overcome these problems in TMM, the probability matching method (PMM) was developed to match nonsynchronous datasets of $Z_{e}$ and $R$ using cumulative density functions (CDF) (Calheiros and Zawadzki, 1987; Atlas et al., 1990; Rosenfeld et al., 1993). The PMM eliminates the sampling volume, collocation and timing errors by matching $Z_{e}$ and $R$ pairs of non-synchronous $Z_{e}$ and $R$ datasets that have the same CDF. This method provides better results in estimating $Z_{e}-R$ relationships for non-synchronous $Z_{e}$ and $R$ datasets as compared to TMM (Atlas et al., 1997). However, Krajewski and Smith (1991) found that the TMM is still significantly superior, providing much higher rain estimation accuracy, as compared to PMM for estimating $Z_{e}-R$ relationships of synchronous $Z_{e}-R$ pairs. Rosenfeld et al. (1994) developed the window probability matching method (WPMM) to surmount weaknesses of the PMM by matching $Z_{e}$ and $R$ pairs within small space and time windows to encompass the collocation and synchronization uncertainties. The WPMM provided significantly improved results in estimating the rain intensity. The advantage of PMM and WPMM is that there is no requirement of concurrent $Z_{e}$ and $R$ datasets while the disadvantages are that these techniques do not represent the real physical process of rainfall and they do not use joint probability between $Z_{e}$ and $R$ datasets.

The accuracy of radar rainfall estimates is particularly important when these estimates must be computed as input to a hydrological model (Borga, 2002). The $Z_{e}-R$ conversion error is an important issue which affects the accuracy of the estimation of $Z_{e}-R$ relationship and radar-measured rainfall. In order to minimize synchronization and collocation uncertainties in $Z_{e}-R$ pairs matching and to address the shortcomings of PMM and WPMM, the present study aimed to develop a method to improve estimation of the $Z_{e}-R$ relationships of non-synchronous $Z_{e}-R$ pairs by accounting for collocation and timing errors. This new method is compared with three other methods, namely TMM, PMM and WPMM. The accuracy of radar rainfall estimates is evaluated using rain gauge-based estimates of point rainfall and mean areal rainfall. The study area is a mountainous watershed in the north of Thailand where rain gauge observations are available from a dense rain gauge network and digital radar data is available from a weather radar installed in the vicinity.

\section{Study area and data collection}

\subsection{Description of the study area}

The study area, Mae Chaem Watershed is located in the north of Thailand with a geographical area of $3853 \mathrm{~km}^{2}$ (Fig. 1). The study watershed is contained within $18^{\circ} 06^{\prime}-$ $19^{\circ} 10^{\prime} \mathrm{N}$ and $98^{\circ} 04^{\prime}-98^{\circ} 34^{\prime} \mathrm{E}$ which comprises mountainous and forested terrain. The highest point in the Mae Chaem Watershed is the Doi Inthanon summit, $2565 \mathrm{~m}$ above the mean sea level, the highest altitude in Thailand. The lowest point in the watershed is $282 \mathrm{~m}$ above the mean sea level. The water flows through the Mae Chaem Watershed areas for $135 \mathrm{~km}$ before joining the Ping River, one of the tributaries of the Chao Phraya River, the main river of Thailand. Rainfall in this region is characterized by a large seasonal and interannual variation. The average annual rainfall in the study area varies from 1000 to $1200 \mathrm{~mm}$ and more than $80 \%$ of it occurs during the southwest monsoon and tropical cyclones. Kuraji et al. (2004) and Dairaku et al. (2002) reported that the rainfall in the Mae Chaem Watershed is orographic. The average annual runoff at the watershed outlet is $1075 \times 10^{6} \mathrm{~m}^{3}$ and about $70 \%$ of it occurs during the rainy season from May to October.

\subsection{Gauge and radar data}

The GEWEX Asian Monsoon Experiment - Tropics (GAME-T) project from 1996-2001 established a rain gauge network in the Mae Chaem Watershed to observe rainfall in this mountainous area since 1997 (Kuraji et al., 1998). Automatic tipping bucket type rain gauges $(20 \mathrm{~cm}$ orifice diameter and $0.5 \mathrm{~mm}$ per tip) with pulse-count time-recording data loggers (one second time resolution) were installed at 13 sites in the watershed. At the outlet of the watershed (Fig. 1), a river flow gauging station (P. 14) is also being operated by the Royal Irrigation Department (RID) of Thailand.

Radar data in this research was obtained from the meteorological radar installed in 1991 on top of a mountain at Om Koi ( $\left.17^{\circ} 47^{\prime} 53 \mathrm{~N}, 98^{\circ} 25^{\prime} 57 \mathrm{E}\right)$ in northern Thailand (Fig. 1). The Bureau of the Royal Rainmaking and Agricultural Aviation, Thailand, operates the Om Koi Radar station for routine observations. The radar is an S-Band Doppler weather surveillance radar system (DWSR-88S model), with the following principal characteristics: frequency $2.7-2.9 \mathrm{GHz}$, wavelength $10.8 \mathrm{~cm}$, peak power $500 \mathrm{~kW}$, antenna diameter $6.1 \mathrm{~m}$ and beam width $1.2^{\circ}$. The data was obtained at $5 \mathrm{~min}$ interval with a $250 \mathrm{~km}$ observation range, $1 \mathrm{~km}$ radial resolution, and $1^{\circ}$ azimuthally resolutions. The radar reflectivity data used in this study was extracted from the CAPPI (Constant Altitude Plan Position Indicator) radar product at an elevation of $3.0 \mathrm{~km}$ above the mean sea level in order to avoid ground clutter and ground echoes problems near the radar site. 


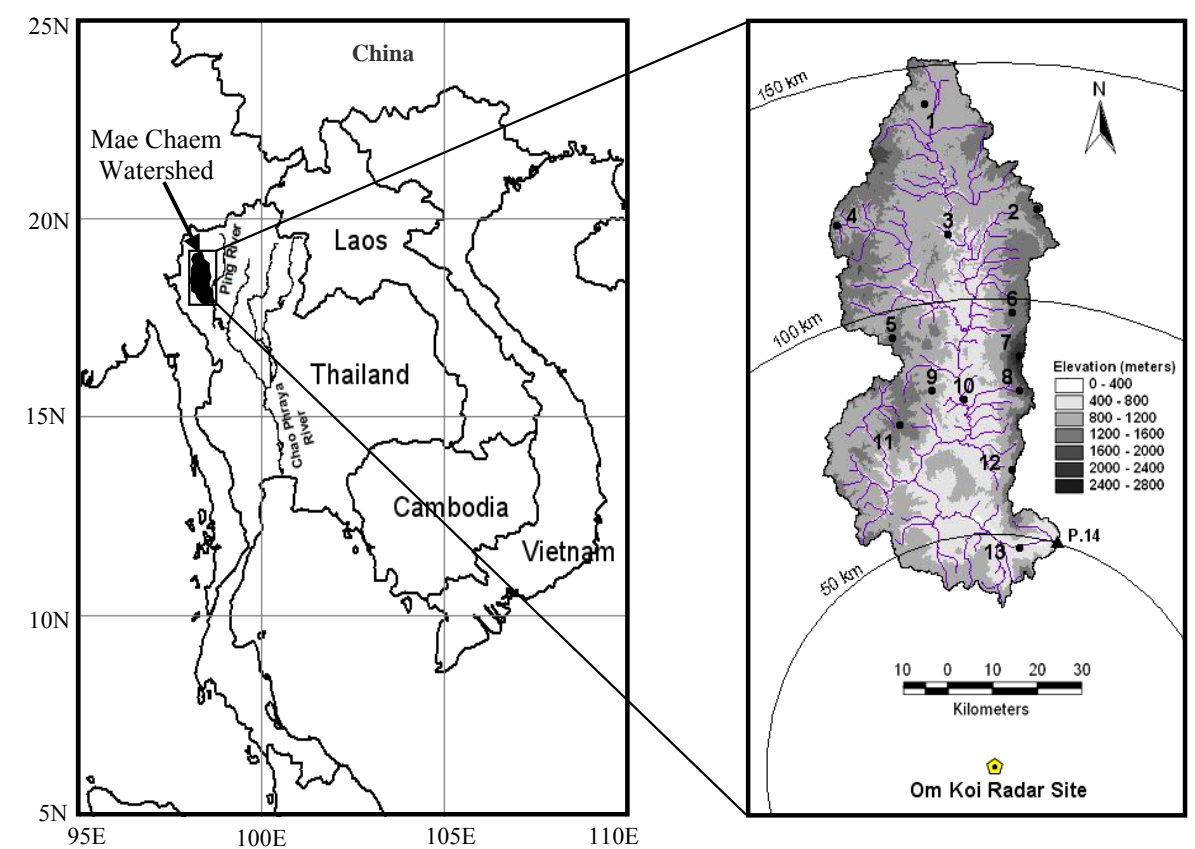

Fig. 1. Mae Chaem Watershed and locations of radar and gauge stations.

The continuous gauge record of rainfall during 15-18 September 1999 at each of the 13 rain gauges was used to calculated rain intensity values of 5 min duration and they are paired with the corresponding $5 \mathrm{~min}$ reflectivity values measured by radar for determining the $Z_{e}-R$ relationship. All the rainfall events within the $86 \mathrm{~h}$ of 13 individual rainfall measuring sites were used to develop the representative $Z_{e}-R$ relationship for the entire study watershed of $3853 \mathrm{~km}^{2}$. The calibrated relationship was then verified using the rainfall event observed during 11-14 September 2000. Table 1 presents the characteristics of rainfall observed at the 13 rain gauge stations in the study watershed for the two rainfall events used for the calibration and verification.

\section{$3 \quad Z_{e}-R$ matching techniques}

\subsection{Traditional matching method (TMM)}

The approach of TMM consists of matching the value of $Z_{e}$ over a rain gauge station with $R$ at the corresponding time of measurement (Fig. 2). This method assumes that the raindrops fall absolutely vertical from the atmosphere to the rain gauges and that the radar rain intensity at the measured altitude is the same as at the surface (Calheiros and Zawadzki, 1987).

\subsection{Probability matching method (PMM)}

The probability matching method was proposed by Calheiros and Zawadzki (1987) to bypass sampling volume, timing and

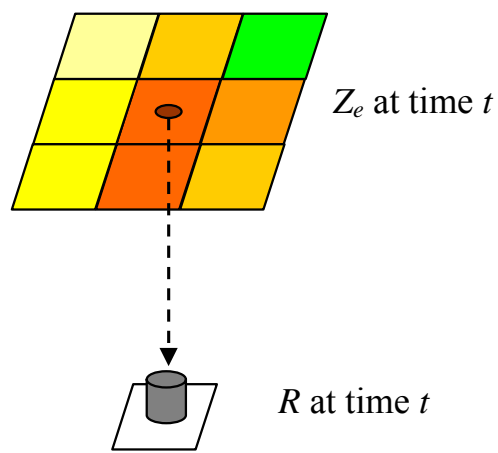

Fig. 2. The traditional $Z_{e}-R$ matching method (TMM).

collocation problems in radar-gauge point comparison. In PMM, it is assumed that the radar observed reflectivity has the same probability of occurrence as the gauge-measured rain intensity (Atlas et al., 1990; Rosenfeld et al., 1993). The setting of $Z_{e}-R$ pairs using this method is therefore based on matching the CDFs of gauge rainfall intensities and radar measured reflectivity values as described in Eq. (1) and shown in Fig. 3.

$$
\int_{R_{i}}^{\infty} P(R) d R=\int_{Z_{e i}}^{\infty} P\left(Z_{e}\right) d Z_{e}
$$

where $P(R)$ is the probability density function of gaugemeasured rainfall intensities and $P\left(Z_{e}\right)$ is the probability density function of measured reflectivity values by radar. To 
Table 1. Characteristics of rainfall observed at 13 rain gauges in the study watershed.

\begin{tabular}{lcc}
\hline Description & Calibration & Verification \\
\hline Period & 15-18 September 1999 & 11-14 September 2000 \\
Rain type & Orographic & Orographic \\
$\begin{array}{l}\text { Duration (h) } \\
\text { Maximum gauge-measured rain intensity } \\
\text { of 5 min duration (mm/h) }\end{array}$ & 86 & 75 \\
$\begin{array}{l}\text { Maximum gauge-measured rain intensity } \\
\text { of 1 h duration (mm/h) }\end{array}$ & 38.0 & 84 \\
$\begin{array}{l}\text { Accumulated gauge mean areal rainfall } \\
\text { by Thiessen polygons (mm) }\end{array}$ & 72.9 & 37.5 \\
\hline
\end{tabular}

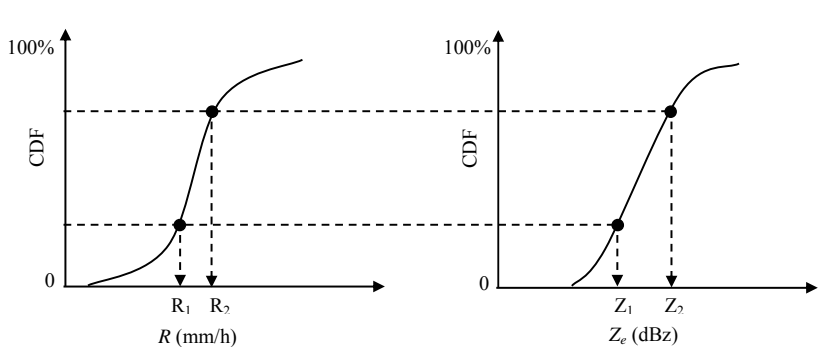

Fig. 3. The probability matching method (PMM).

construct CDF of $Z_{e}$ and $\mathrm{R}$, the datasets of $Z_{e}$ and $R$ are determined as explained earlier in TMM. $R_{i}$ and $Z_{i}$ having the same CDF values are matched as pairs and then these pairs are used to determine the $Z_{e}-R$ relationship. This method eliminates timing errors because PMM does not make use of the actual time at which each pair of $R$ and $Z_{e}$ occurred and the geometric errors are eliminated as long as raindrops at the radar pixel over the rain gauge fall absolutely vertical. However, the disadvantage of PMM is that this method does not consider the joint distribution or inter-association between $Z_{e}$ and $R$.

\subsection{Window probability matching method (WPMM)}

The window probability matching method was developed by Rosenfeld et al. (1994) to reduce geometrical mismatch and synchronization error in $Z_{e}$ and $R$ pair matching where $Z_{e}$ is obtained from the space windows, centered over the coordinates of the rain gauges, and $R$ is taken from the gauge time windows, centered at time $t$ of the radar scan as illustrated in Fig. 4. The values of $Z_{e}$ and $R$ from the space and time windows are then contributed to the $P\left(Z_{e}\right)$ and $P(R)$ to match $Z_{e}$ and $R$ at the same percentile. In this way the closest possible synchronization between the radar and gauge observations may be obtained and one may be assured that the radar observations aloft correspond to the rain measurements at the surface in spite of possible navigation errors and displacement of the rain from the center of the radar window

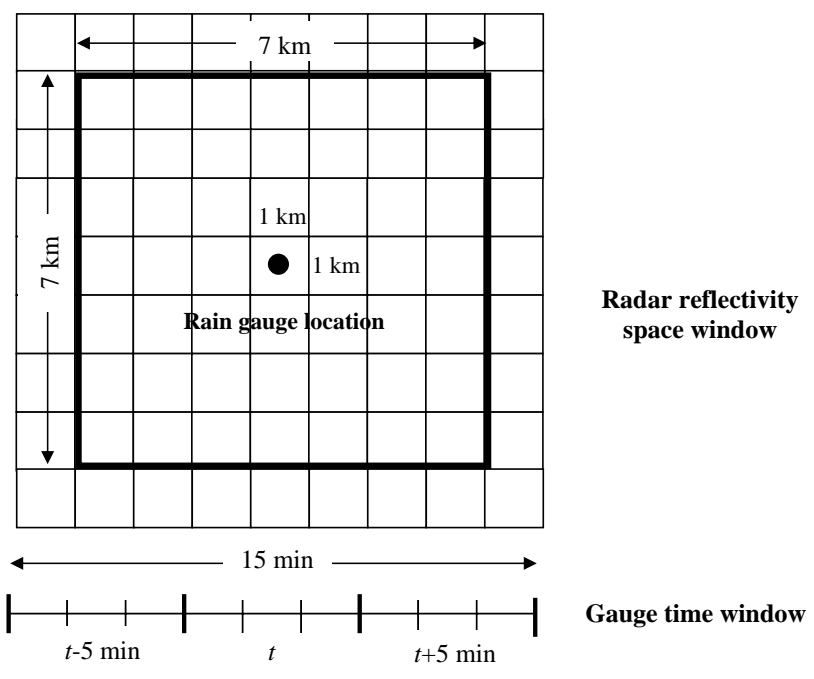

Fig. 4. The window probability matching method (WPMM).

by the wind. This also increases the number of $Z_{e}-R$ pairs and thus the accuracy of the estimated $Z_{e}-R$ relationship. In this study, forty-nine reflectivity values within $7 \times 7 \mathrm{~km}$ of radar space window and three gauge rain intensity values of 5-min gauge time window (Fig. 4) were used in the WPMM procedure.

\subsection{Window correlation matching method (WCMM)}

WCMM was developed to match $Z_{e}-R$ pairs when collocation and timing errors are present (non-synchronous $Z_{e}-R$ datasets). These errors are caused by wind and the height of radar measurement, respectively. This method attempts to account for the physical process of rainfall as the raindrops rarely fall absolutely vertically due to wind effects, and also radar measurements are taken at a higher altitude from the ground, so that it is necessary to consider the travel time of raindrops. Moreover, the WCMM uses concurrent $Z_{e}$ and $R$ datasets to develop the representative reflectivity-rain intensity relationship. The concept of this method is the extension 
Table 2. WCMM scenariosanalyzed and the number of $Z_{e}$ values.

\begin{tabular}{cccc}
\hline & \multicolumn{3}{c}{ Time window (min) } \\
\cline { 2 - 4 } $\begin{array}{c}\text { Space window } \\
(\mathrm{km})\end{array}$ & 0 & $0,-5$ & $0,-5,-10$ \\
\hline $3 \times 3$ & S33T0 (9) & S33T5 $(18)$ & S33T10 (27) \\
$5 \times 5$ & S55T0 (25) & S55T5 (50) & S55T10 (75) \\
$7 \times 7$ & S77T0 (49) & S77T5 (98) & S77T10 (147) \\
$9 \times 9$ & S99T0 (81) & S99T5 (162) & S99T10 (243) \\
\hline
\end{tabular}

Note: The figure in parentheses is the number of $Z_{e}$ values considered in the analysis.

of possible matching areas of $Z_{e}$ from the traditional matching method for searching and finding the optimal $Z_{e}$ that gives the best correspondence with $R$. The possible matching areas in this method consist of the space and time windows as shown in Fig. 5. The purpose of the space window is to reduce the geometric mismatch that is affected by wind, while the time window is to account for a timing error which is mainly affected by the height of radar measurement.

The process of WCMM consists of matching $Z_{e}$ values within the space and time windows to reference gauge rainfall intensity and searching for the value of $Z_{e}$ of the radar pixel that gives the maximum correlation coefficient $(r)$ as expressed in Eqs. (2) and (3). This $Z_{e}$ value is then assigned to match the reference gauge rainfall intensity. This $Z_{e}-R$ pair is called "the optimal $Z_{e}-R$ pair".

$r=\frac{\operatorname{cov} Z_{e} R}{S_{Z e} S_{R}}$

$\operatorname{cov} Z_{e} R=\frac{\sum_{i=1}^{n}\left(\left(Z_{i}-\overline{Z_{e}}\right) x\left(R_{i}-\bar{R}\right)\right)}{(n-1)}$,

where $Z_{i}$ is $Z_{e}$ value of non-zero $Z_{e}-R$ pair $i, \bar{Z}$ is the mean value of $Z_{e}$ data, $R_{i}$ is $R$ value of non-zero $Z_{e}-R$ pair $i, \bar{R}$ is the mean value of $R$ data, $S_{Z e}$ is the standard deviation of $Z_{e}$ data, $S_{R}$ is the standard deviation of $R$ data and $n$ is the number of non-zero $Z_{e}-R$ pairs over the $86 \mathrm{~h}$ of the 13 rain gauge sites. The WCMM process is illustrated in Fig. 6. The size of the space and time windows must be large enough to account for collocation and timing errors.

For the value of $r=1$, the $Z_{e}-R$ pairs are perfectly synchronized, while a value of $r=0$, means that the $Z_{e}-R$ pairs do not have a relationship at all. The WCMM allows matching the values of $Z_{e}$ of the radar pixels surrounding the reference rain gauge or measured in the previous time intervals with $R$.

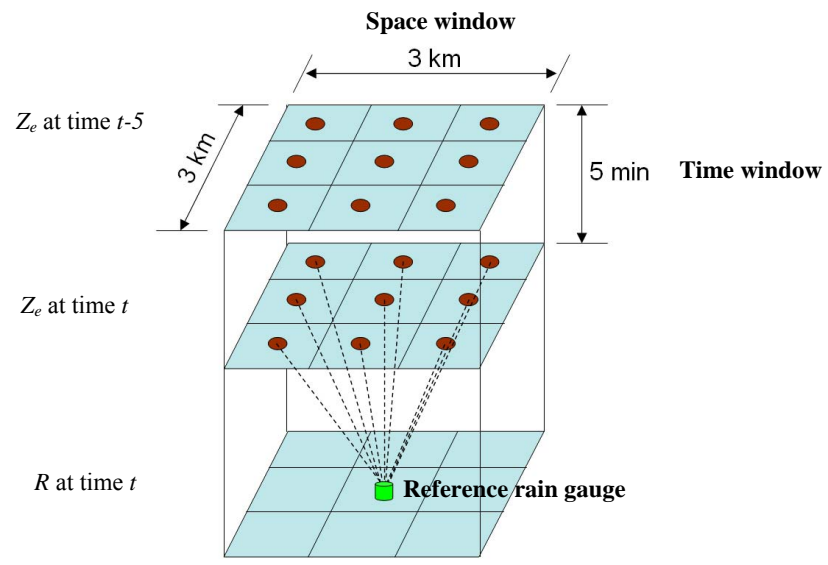

Fig. 5. The concept of the window correlation matching method (WCMM).

\section{Evaluation of $Z_{e}-R$ relationships}

\subsection{Comparison of various WCMM scenarios}

Twelve WCMM scenarios were investigated in this study for matching $Z_{e}-R$ pairs and identifying the optimal $Z_{e}-R$ pairs. The sizes of the space windows used were $3 \times 3,5 \times 5$ $7 \times 7$ and $9 \times 9$ radar grid pixels which cover an area of 9 , 25,49 and $81 \mathrm{~km}^{2}$, respectively, above the rain gauges. The time windows of radar measurements were set to three sizes which consist of present time that is at the same time as rain gauges measurement $(0 \mathrm{~min})$, a combination of present time and $5 \mathrm{~min}$ previous time $(0$ and $-5 \mathrm{~min})$ and a combination of present time, 5 and $10 \mathrm{~min}$ previous times $(0,-5$ and $-10 \mathrm{~min}$ ). These scenarios are defined in Table 2 . The number of $Z_{e}$ values for finding optimal $Z_{e}$ that gives the best correspondence with $R$ with respect to the given space and time windows are presented in parenthesis in Table 2.

Fifteen rain intensity values of $5 \mathrm{~min}$ duration which vary from 0.5 to $7.5 \mathrm{~mm} / 5 \mathrm{~min}$ ( 6 to $90 \mathrm{~mm} / \mathrm{h}$ ) with the increment of $0.5 \mathrm{~mm} / 5 \mathrm{~min}(6 \mathrm{~mm} / \mathrm{h})$ were considered over the $86 \mathrm{~h}$ period with the 13 rain gauges stations. This gave a total of 627 non-zero $Z_{e}-R$ pairs. The scatter plots of these $Z_{e}-R$ pairs for the twelve WCMM scenarios are depicted in Fig. 7. It is found that when the space and time window size is increased, the degree of scatter of $Z_{e}-R$ pairs reduces. However, it can be seen that the scatter plot of the $9 \times 9 \mathrm{~km}$ of the space window (S99) has no significant improvement as compared to the $7 \times 7 \mathrm{~km}$ of the space window (S77). Similarly, the increase in time window from 5 to 10 min previous time also has not reduced the degree of scatter of $Z_{e}-R$ pairs. The degree of fit of the relationship of $Z_{e}-R$ pairs based on various WCMM scenarios was measured in terms of correlation coefficient (Eqs. 2 and 3) and the results are presented in Table 3 . 


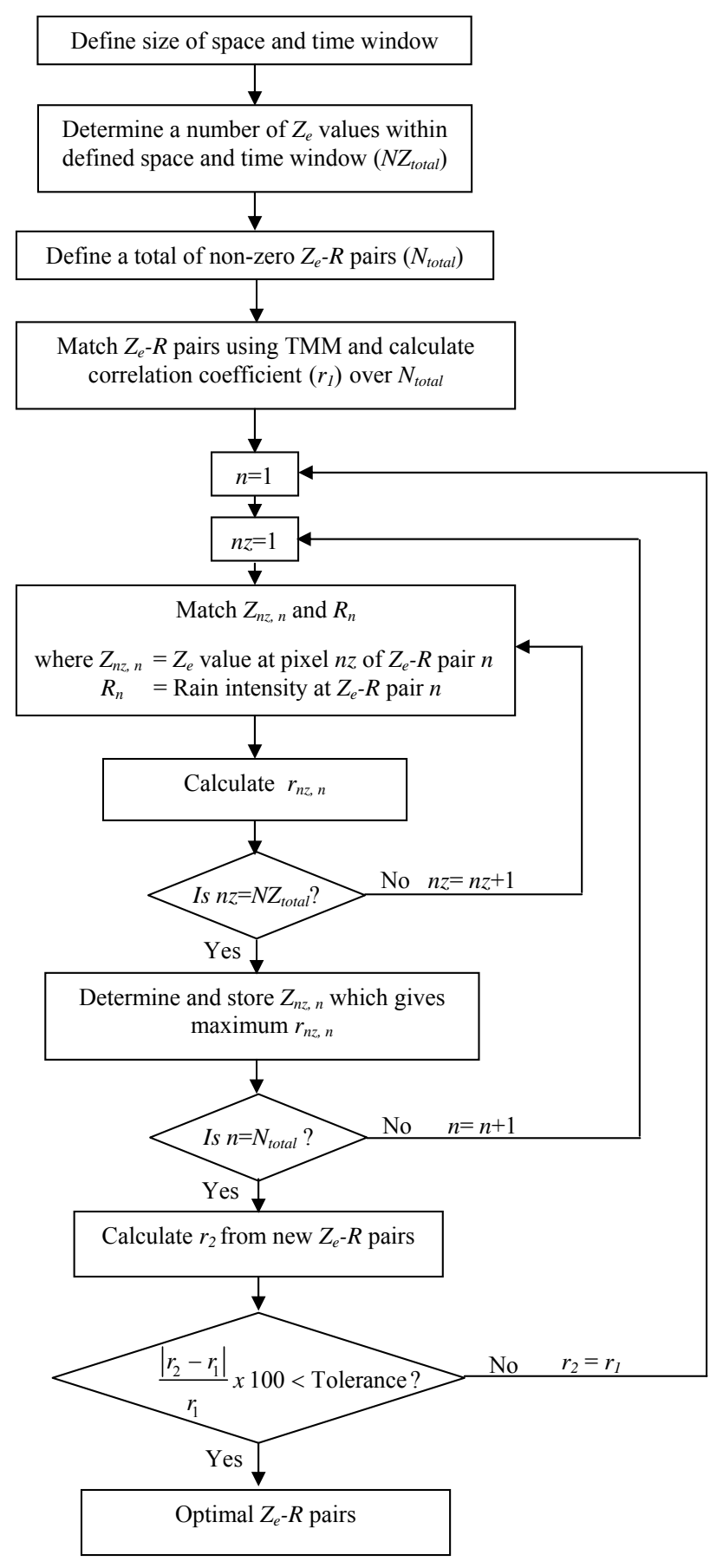

Fig. 6. The WCMM process.

The $r$ values increase significantly when the space window in WCMM is expanded from $3 \times 3$ to $5 \times 5 \mathrm{~km}$ for the different time windows considered. The percentage increase varies from $10.68-28.88 \%$. However, the $r$ values have slightly increased when the space window is enlarged to $7 \times 7 \mathrm{~km}$. The change is about $2 \%$ as compared to $5 \times 5 \mathrm{~km}$ of the space window. Further increase in the space window to $9 \times 9 \mathrm{~km}$
Table 3. Correlation coefficient of $Z_{e}-R$ pairs for different WCMM scenarios.

\begin{tabular}{cccc}
\hline \multirow{2}{*}{$\begin{array}{c}\text { Space window } \\
(\mathrm{km})\end{array}$} & \multicolumn{3}{c}{ Time window (min) } \\
\cline { 2 - 4 } & 0 & $0,-5$ & $0,-5,-10$ \\
\hline $3 \times 3$ & 0.644 & 0.765 & 0.769 \\
$5 \times 5$ & 0.830 & 0.848 & 0.850 \\
$7 \times 7$ & 0.845 & 0.868 & 0.870 \\
$9 \times 9$ & 0.846 & 0.869 & 0.870 \\
\hline
\end{tabular}

has very small increase in the $r$ values. On the other hand, when the time widow is extended from present time to previous $5 \mathrm{~min}$ of radar measurement, the $r$ values have increased slightly except in the S33T5 scenario (Table 2) where an increase of $18.79 \%$ as compared with S33T0 is observed. The increases in $r$ values for the other scenarios are about 2-3\%. The results indicate a small increase in $r$ values when previous $10 \mathrm{~min}$ of radar observation is added in the time window of WCMM. The increase in the $r$ values is less than $0.5 \%$. The use of $9 \times 9 \mathrm{~km}$ of the space window and previous $10 \mathrm{~min}$ of radar observations in the time window has no significant improvement in the relationship of $Z_{e}-R$ pairs. Based on the results, it can be concluded that when the space and time window size of WCMM are increased, the relationship between $Z_{e}$ and $R$ is improved. Moreover, the S77T5 scenario (using a $7 \times 7 \mathrm{~km}$ of the space window and a combination of present time and previous $5 \mathrm{~min}$ radar scan in time window) is sufficient to correct collocation and timing errors in $Z_{e}-R$ pairs.

\subsection{Estimation of $a$ and $b$ parameters in $Z_{e}-R$ relationship}

The relationship between $Z_{e}-R$ is usually represented in term of empirical power law equation (Marshall and Palmer, 1948; Joss et al., 1970; Collier, 1996; Rosenfeld et al., 1993) as below,

$Z_{e}=a R^{b}$,

where $Z_{e}$ is measured radar reflectivity in $\mathrm{mm}^{6} / \mathrm{m}^{3}, R$ is rainfall intensity in $\mathrm{mm} / \mathrm{h}$, and $a$ and $b$ are parameters. The parameters $a$ and $b$ in the power law equation were estimated for different WCMM scenarios and the results are presented in Table 4.

Table 4 indicates that with increase in space and time window size of WCMM, the value of parameter $a$ decreases whereas the value of parameter $b$ increases. However, parameter $b$ does not vary much as compared to parameter $a$. Moreover, the values of parameters $a$ and $b$ remain nearly the same when the space window is expanded from $7 \times 7 \mathrm{~km}$ to $9 \times 9 \mathrm{~km}$ and also when the time window is extended from previous $5 \mathrm{~min}$ to $10 \mathrm{~min}$ of radar measurement. It can be said that increasing the space window to $9 \times 9 \mathrm{~km}$ and adding the 

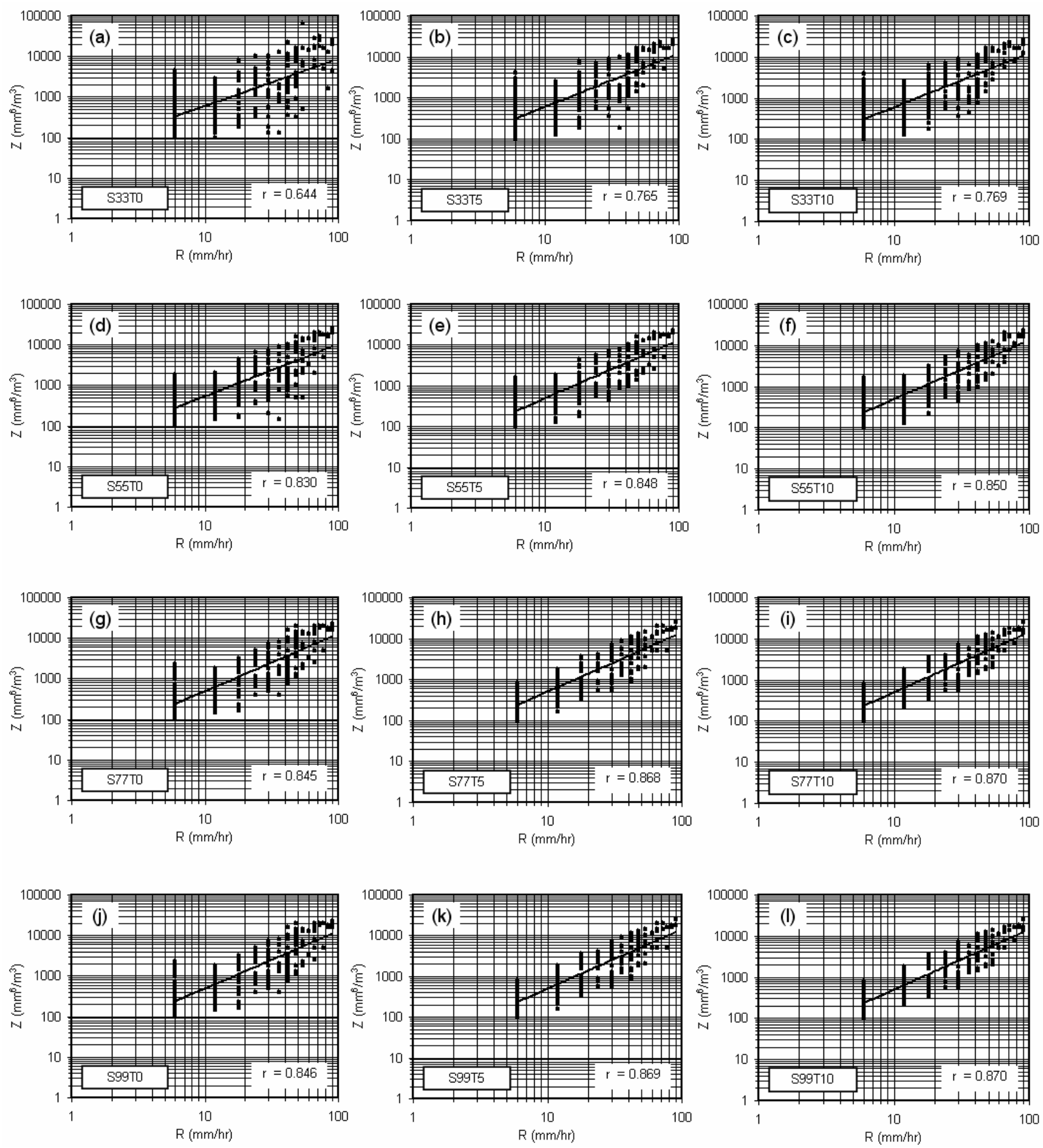
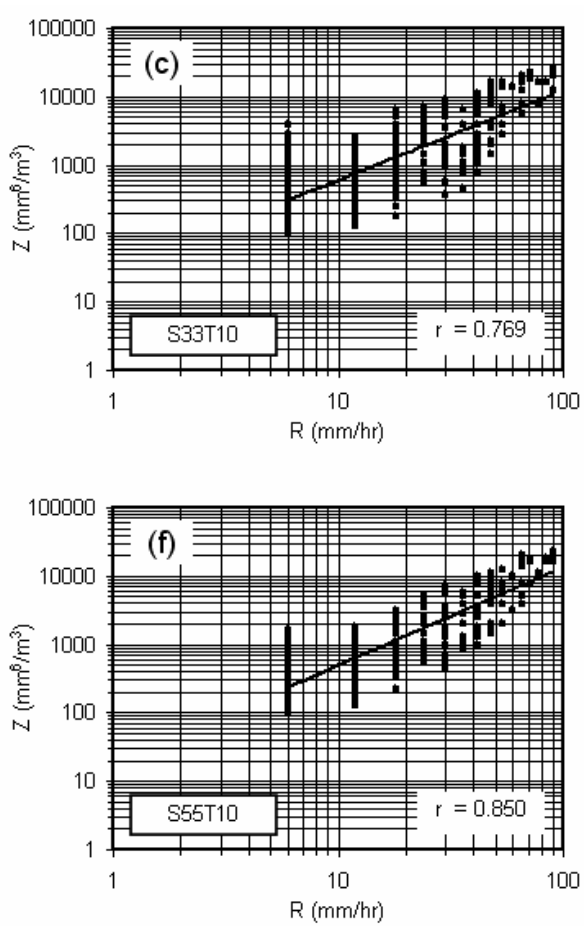

00

Fig. 7. Scatter plots of $Z_{e}-R$ pairs for different WCMM scenarios during 15-18 September 1999.

previous $10 \mathrm{~min}$ of radar observation in the time window in WCMM has no significant change in the values of parameters $a$ and $b$ in $Z_{e}-R$ relationship considered in the study. These results also suggest that $7 \times 7 \mathrm{~km}$ of the space window and a combination of present time and previous 5 min radar scan in time window in WCMM can account for collocation and timing errors that occurred due to wind effects and the difference in height of measurements by radar and rain gauges. 
Table 4. Parameters $a$ and $b$ in $Z_{e}-R$ relationship (Eq. 4) for different WCMM scenarios.

\begin{tabular}{cccccccc}
\hline \multirow{2}{*}{$\begin{array}{c}\text { Space window } \\
(\mathrm{km})\end{array}$} & \multicolumn{6}{c}{ Time window (min) } \\
\cline { 2 - 8 } & \multicolumn{2}{c}{0} & \multicolumn{2}{c}{$0,-5$} & \multicolumn{2}{c}{$0,-5,-10$} \\
\cline { 2 - 8 } & $a$ & $b$ & $a$ & $b$ & $a$ & $b$ \\
\hline $3 \times 3$ & 42.44 & 1.157 & 30.59 & 1.298 & 30.48 & 1.302 \\
$5 \times 5$ & 26.35 & 1.305 & 19.04 & 1.422 & 19.00 & 1.424 \\
$7 \times 7$ & 18.60 & 1.423 & 18.05 & 1.450 & 18.02 & 1.451 \\
$9 \times 9$ & 18.58 & 1.425 & 18.04 & 1.450 & 18.02 & 1.451 \\
\hline
\end{tabular}

Table 5. Mean absolute error (MAE) in rainfall intensity and rainfall depth for different WCMM scenarios.

\begin{tabular}{ccccccc}
\hline \multirow{2}{*}{$\begin{array}{c}\text { Space window } \\
(\mathrm{km})\end{array}$} & \multicolumn{5}{c}{ Time window (min) } \\
\cline { 2 - 7 } & \multicolumn{2}{c}{0} & \multicolumn{2}{c}{$0,-5$} & $0,-5,-10$ \\
\cline { 2 - 7 } & $\begin{array}{c}\text { Rain intensity } \\
(\mathrm{mm} / \mathrm{h})\end{array}$ & $\begin{array}{c}\text { Rain depth } \\
(\mathrm{mm})\end{array}$ & $\begin{array}{c}\text { Rain intensity } \\
(\mathrm{mm} / \mathrm{h})\end{array}$ & $\begin{array}{c}\text { Rain depth } \\
(\mathrm{mm})\end{array}$ & $\begin{array}{c}\text { Rain intensity } \\
(\mathrm{mm} / \mathrm{h})\end{array}$ & $\begin{array}{c}\text { Rain depth } \\
(\mathrm{mm})\end{array}$ \\
\hline $3 \times 3$ & 13.81 & 48.14 & 9.41 & 29.79 & 9.32 & 27.32 \\
$5 \times 5$ & 9.15 & 22.28 & 7.58 & 12.42 & 7.50 & 12.36 \\
$7 \times 7$ & 7.80 & 13.31 & 6.59 & 8.56 & 6.58 & 8.54 \\
$9 \times 9$ & 7.78 & 13.27 & 6.59 & 8.56 & 6.58 & 8.54 \\
\hline
\end{tabular}

\subsection{Comparison of radar- and gauge-measured rainfall}

In order to find out which space and time window sizes in WCMM give the best results for radar rainfall estimates as compared with the gauge rainfall, the performances of estimated $Z_{e}-R$ relationships from different WCMM scenarios are also evaluated in this study with two approaches described in the following sections.

\subsubsection{Point rainfall estimates}

The estimations of radar rainfall intensities of 5 min duration over 13 rain gauges in the Mae Chaem Watershed using the estimated $Z_{e}-R$ relationships for different WCMM scenarios were compared with the observed gauge rainfall intensities as point rainfall measurements. The performance of different estimated $Z_{e}-R$ relationships was evaluated using the mean absolute error (MAE) as expressed below,

$\operatorname{MAE}=\frac{1}{n} \sum_{i=1}^{n}\left|R_{i}-G_{i}\right|$,

where $R_{i}$ is radar rainfall intensity in $\mathrm{mm} / \mathrm{h}$ or total depth of radar rainfall in $\mathrm{mm}, G_{i}$ is gauge rainfall intensity in $\mathrm{mm} / \mathrm{h}$ or total depth of gauge rainfall in $\mathrm{mm}$ and $n$ is the number of data pairs of 13 rain gauges. The results of MAE are presented in Table 5. It is seen that the increase in the space window in WCMM from $3 \times 3$ to $5 \times 5$ and $7 \times 7 \mathrm{~km}$ decreases
MAE of radar-measured rainfall. However, further increase to $9 \times 9 \mathrm{~km}$ has no improvement in MAE for all the time window scenarios analyzed. Furthermore, when the time window in WCMM is extended from present time to previous $5 \mathrm{~min}, \mathrm{MAE}$ also reduces. However, relatively much less reduction in MAE is observed when previous $10 \mathrm{~min}$ of radar observation in the time widow is considered compared to the present time and previous 5 min of radar scan in the time widow in WCMM.

In addition, the total depths of rainfall of 13 rain gauges over $86 \mathrm{~h}$ are compared with radar rainfall estimates using the MAE statistic (Eq. 5) as also presented in Table 5. The results are similar to the comparison of radar and gauge rainfall intensity. The enlargement of space and time windows from $3 \times 3$ to $7 \times 7 \mathrm{~km}$ and present time to previous 5 min improves the estimation of $Z_{e}-R$ relationship and radar rainfall. Using $9 \times 9 \mathrm{~km}$ of space window and previous $10 \mathrm{~min}$ of radar scanning in time window also has no significant reduction in MAE. Therefore, in this study, it can be concluded that the $Z_{e}-R$ relationship estimated based on S77T5 provides the best estimates of point radar rainfall as compared with the rain gauge data with MAE of $6.59 \mathrm{~mm} / \mathrm{h}$ for rainfall intensity and $8.56 \mathrm{~mm}$ for the total rainfall depth. 

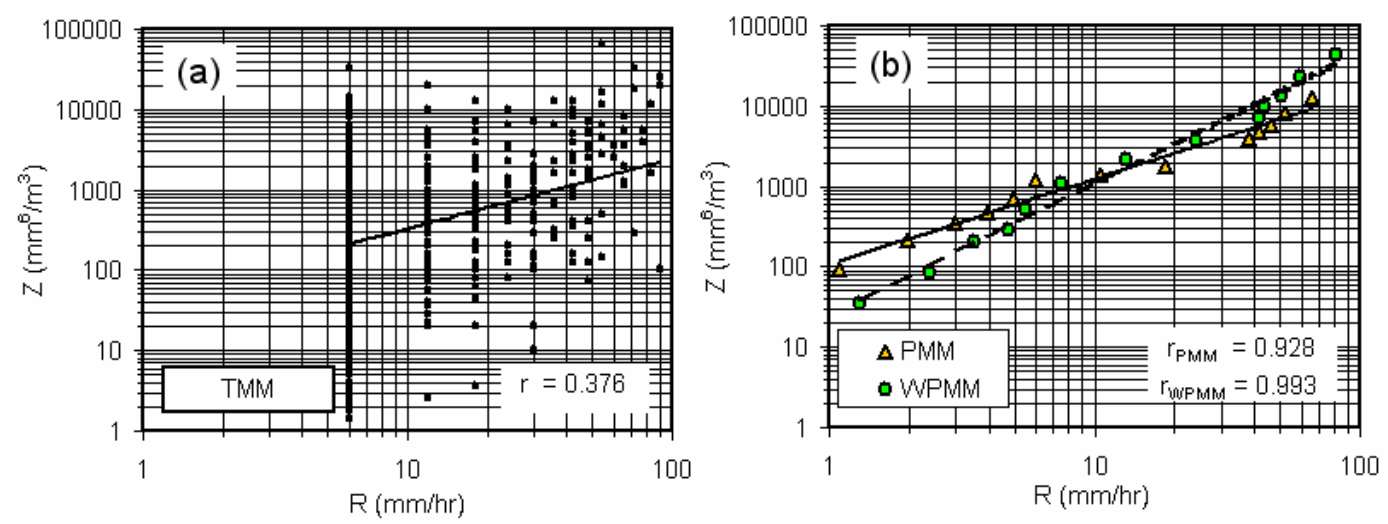

Fig. 8. Scatter plot of $Z_{e}-R$ pairs based on TMM (a), PMM and WPMM (b) during 15-18 September 1999.

Table 6. Cumulative mean areal rainfall (CMAR) and $\mathrm{PD}_{\mathrm{CMAR}}$ for different WCMM scenarios.

\begin{tabular}{|c|c|c|c|c|c|c|c|}
\hline \multicolumn{7}{|c|}{ Radar } & \multirow{4}{*}{ Rain gauge (mm) } \\
\hline \multirow{3}{*}{$\begin{array}{l}\text { Space window } \\
(\mathrm{km})\end{array}$} & \multicolumn{6}{|c|}{ Time window (min) } & \\
\hline & \multicolumn{2}{|c|}{0} & \multicolumn{2}{|c|}{$0,-5$} & \multicolumn{2}{|c|}{$0,-5,-10$} & \\
\hline & CMAR (mm) & $\operatorname{PD}_{\mathrm{CMAR}}(\%)$ & CMAR (mm) & $\operatorname{PD}_{\text {CMAR }}(\%)$ & CMAR (mm) & $\operatorname{PD}_{\mathrm{CMAR}}(\%)$ & \\
\hline $3 \times 3$ & 83.8 & 15.0 & 78.6 & 7.8 & 78.3 & 7.4 & \multirow{4}{*}{72.9} \\
\hline $5 \times 5$ & 80.5 & 10.4 & 75.4 & 3.4 & 75.2 & 3.2 & \\
\hline $7 \times 7$ & 76.9 & 5.5 & 70.7 & -3.0 & 70.7 & -3.0 & \\
\hline $9 \times 9$ & 76.8 & 5.3 & 70.7 & -3.0 & 70.7 & -3.0 & \\
\hline
\end{tabular}

Note: $\mathrm{PD}_{\mathrm{CMAR}}$ is the percentage difference of cumulative mean areal rainfall between the radar and the rain gauge data.

\subsubsection{Mean areal rainfall estimates}

A comparison of cumulative mean areal rainfall (CMAR) estimates over the whole area of the Mae Chaem Watershed during 15-18 September 1999 (86h) obtained using the Thiessen polygon technique with 13 rain gauges data (dense rain gauge network) and from the radar data using the different $Z_{e}-R$ relationships that are estimated based on several WCMM scenarios (Table 4) is presented in Table 6. The percentage difference of cumulative mean areal rainfall $\left(\mathrm{PD}_{\mathrm{CMAR}}\right)$ between the radar and the rain gauge data is determined using Eq. (6) and the results are also given in Table 6.

$$
\operatorname{PD}_{\mathrm{CMAR}}(\%)=\frac{\left(\mathrm{CMAR}_{\text {radar }}-\mathrm{CMAR}_{\text {gauge }}\right)}{\mathrm{CMAR}_{\text {gauge }}} \times 100,
$$

In Eq. (6), $\mathrm{CMAR}_{\text {radar }}$ and $\mathrm{CMAR}_{\text {gauge }}$ are the cumulative mean areal radar and guage rainfall, respectively, in $\mathrm{mm}$. The positive and negative values of $\mathrm{PD}_{\mathrm{CMAR}}$ mean that $\mathrm{cu}$ mulative mean areal radar rainfall is overestimated and underestimated, respectively, compared to the estimates based on the Thiessen polygon technique using the 13 rain gauges data. Among the WCMM scenarios, the results from S77T5, S77T10, S99T5 and S99T10 are closest to the estimates based on rain gauge data with a difference of only $-3 \%$ over a period of $86 \mathrm{~h}$. Again, from these results, it is concluded that increasing in the space window from $7 \times 7$ to $9 \times 9 \mathrm{~km}$ and extending the previous $10 \mathrm{~min}$ of radar measurement in the time window in WCMM causes no significant improvement in the mean areal radar rainfall estimates. From these results, it is also confirmed that the S77T5 scenario provides the best results of radar measured rainfall in the present study.

\subsection{Comparison of $Z_{e}-R$ pair matching techniques}

The $Z_{e}-R$ relationship estimated from S77T5 is compared with those estimated from the other three techniques, namely TMM and PMM and WPMM. The $Z_{e}-R$ pairs scatter plot of TMM is shown in Fig. 8a. It can be seen that $Z_{e}$ is poorly related to $R$ with $r$ of 0.376 . The $Z_{e}$ and $R$ datasets of TMM were used in PMM to determine the CDF of gauge rainfall intensities and measured radar reflectivity data. The $Z_{e}$ and $R$ datasets for WPMM were obtained from $7 \times 7$ grid points of radar reflectivity space window and three 5-min rainfall intensities of gauge time window, respectively. The $Z_{e}$ and $R$ in PMM and WPMM that have the same CDF values $(10,20$, $30,40,50,60,70,80,90,92,94,96$, and $98 \%$ ) were matched as pairs as shown in Fig. 8b. Regression analysis was used to estimate the parameters $a$ and $b$ of the empirical formula of 
Table 7. Performance of $Z_{e}-R$ relationships by different $Z_{e}-R$ pair matching techniques.

\begin{tabular}{lcccccc}
\hline$Z_{e}-R$ matching method & \multicolumn{2}{c}{ Parameter } & \multicolumn{2}{c}{ MAE } & CMAR & $\begin{array}{c}\text { PD }_{\text {CMAR }} \\
(\%)\end{array}$ \\
& $a$ & $b$ & $(\mathrm{~mm} / \mathrm{h})$ & $(\mathrm{mm})$ & $(\mathrm{mm})$ & $(\%)$ \\
\hline TMM & 45.85 & 0.861 & 63.10 & 108.94 & 216.0 & 196.3 \\
PMM & 95.52 & 1.134 & 11.30 & 34.28 & 44.0 & -39.6 \\
WPMM & 25.46 & 1.630 & 8.45 & 12.14 & 65.1 & -10.7 \\
S77T5-WCMM & 18.05 & 1.450 & 6.59 & 8.56 & 70.7 & -3.0 \\
\hline
\end{tabular}

Note: MAE is mean absolute error, CMAR is cumulative mean areal rainfall and $\mathrm{PD}_{\mathrm{CMAR}}$ is the percentage difference of cumulative mean areal rainfall between the radar and the rain gauge data.

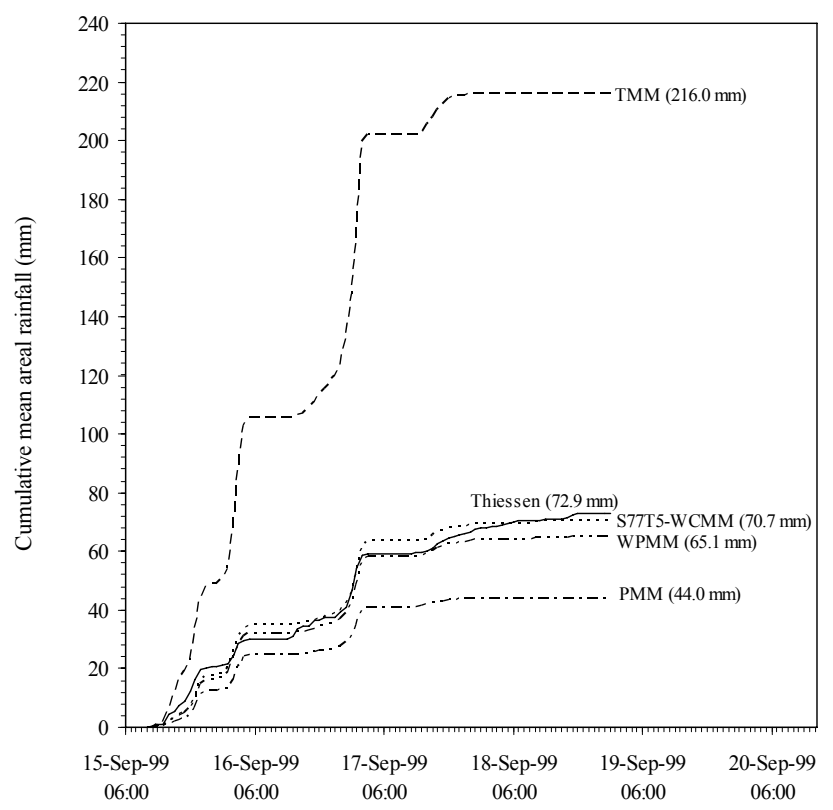

Fig. 9. Cumulative mean areal rainfall estimates based on different $Z_{e}-R$ pair matching techniques.

$Z_{e}-R$ relationship for TMM, PMM and WPMM and the results are presented in Table 7. The performance of the $Z_{e}-R$ relationships derived from the four matching techniques was evaluated in terms of point rainfall and mean areal rainfall estimates by comparing them with the rain gauge data (see Sect. 4.3). The analysis results are also given in Table 7.

The estimated $Z_{e}-R$ relationship from TMM gives the largest MAE of $63.10 \mathrm{~mm} / \mathrm{h}$ and $108.94 \mathrm{~mm}$ in point radar rainfall estimates, as compared to the estimates based on the other three methods, due to unsynchronized $Z_{e}-R$ pairs used in TMM (Fig. 8a). The $Z_{e}-R$ relationship by PMM provides improved estimates of point rainfall compared to those based on TMM. Further improvement in rainfall estimates is observed with WPMM in which the MAE is reduced to $8.45 \mathrm{~mm} / \mathrm{h}$ and $12.14 \mathrm{~mm}$. However, the $Z_{e}-R$ relationship determined based on S77T5 gives the best results of point rainfall estimates with MAE of $6.59 \mathrm{~mm} / \mathrm{h}$ and $8.56 \mathrm{~mm}$ in the rain intensity and amount, respectively.

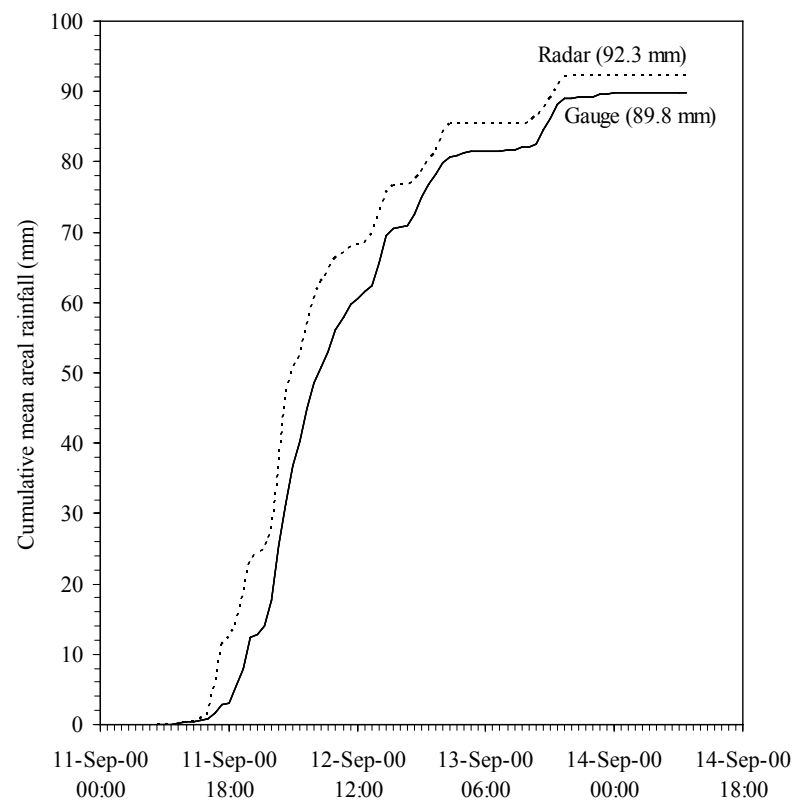

Fig. 10. Cumulative mean areal rainfall estimates based on 13 rain gauges and radar data during 11-14 September 2000 for verification.

The cumulative mean areal rainfall estimates based on different $Z_{e}-R$ pair matching techniques and rain gauges data are compared in Fig. 9. The cumulative mean areal rainfall based on the radar data using $Z_{e}-R$ relationship obtained from TMM is much overestimated, a value of $216.0 \mathrm{~mm}$ compared to $72.9 \mathrm{~mm}$ with the Thiessen polygon method using 13 rain gauges data. The cumulative mean areal rainfall based on PMM is underestimated with the difference of $-39.6 \%$ when compared with the Thiessen polygon method. The WPMM provided better estimates of cumulative mean areal rainfall as compared to TMM and PMM (Table 7 and Fig. 9). Further improved results were obtained with WCMM. The $Z_{e}-R$ relationship determined based on WCMM (S77T5) shows only $-3 \%$ differences in the cumulative mean areal rainfall estimates as compared with the estimates based on rain gauge data. 


\subsection{Verification of $Z_{e}-R$ relationship}

The calibrated $Z_{e}-R$ relationship $\left(Z_{e}=18.05 R^{1.45}\right)$ obtained from S77T5-WCMM is verified using the rainfall event occurred during 11-14 September 2000. Table 1 presents the rainfall characteristics of this event. The accumulated mean areal rainfall of $89.8 \mathrm{~mm}$ over a period of $75 \mathrm{~h}$ is calculated using the Thiessen polygon method with 13 rain gauges. The verification results of radar rainfall estimates are compared with the mean rainfall observed with the rain gauges in Fig. 10. The mean areal radar rainfall matches well that obtained from the rain gauges with a difference of about $3 \%$ in the two measurements. This clearly indicates that the $Z_{e}-R$ relationship developed in the present study can be used with confidence in converting radar reflectivity measurements into the rain intensities in the study area.

\section{Conclusions}

In this study, a method called the window correlation matching method (WCMM) was developed to correct collocation and timing errors in $Z_{e}-R$ pair matching to reduce $Z_{e}-R$ conversion errors in radar-measured rainfall. This method was compared with other three methods, namely the traditional matching method (TMM), the probability matching method (PMM) and the window probability matching method (WPMM). The $Z_{e}-R$ relationship was developed based on $5 \mathrm{~min}$ rain gauge and radar data of orographic rain occurring during 15-18 September 1999 over the Mae Chaem watershed in the north of Thailand and the model results were verified using the rainfall event observed during 11-14 September 2000.

In order to find out which space and time windows in WCMM give the best results for radar rainfall estimates, the size of the space and time windows was varied. The comparison among various WCMM scenarios shows that when the space and time window sizes are increased, the relationship between $Z_{e}$ and $R$ improves. Using $7 \times 7 \mathrm{~km}$ of space window and a combination of present and 5 min previous time of radar observation in the time window (S77T5) provides the best correlation in the matching of $Z_{e}-R$ pairs. The variation of the space and time widow sizes also affects the accuracy of the estimation of $Z_{e}-R$ relationship. The relationship $Z_{e}=18.05 R^{1.45}$ obtained from S77T5 gives the best results of point rainfall estimates with MAE of $6.59 \mathrm{~mm} / \mathrm{h}$ for rainfall intensity and $8.56 \mathrm{~mm}$ for the total depth of rainfall. Also, this $Z_{e}-R$ relationship provides the best estimation of mean areal radar rainfall with a difference in the cumulative mean areal rainfall of $-3 \%$ as compared with the gauge rainfall. These results confirm that S77T5 is large enough to account for collocation and timing errors in $Z_{e}-R$ pair matching that occur due to wind effects and the difference in height of measurement of rainfall by radar and rain gauges.
The $Z_{e}-R$ relationship obtained from TMM provides poor estimation of radar rainfall because of geometrical mismatch and timing errors. The PMM improved the radar rainfall estimates compared to TMM as PMM is based on probability density functions of radar reflectivity values and gaugemeasured rainfall intensities which are derived from the observations. The accuracy of point and mean areal rainfall estimates is considerably improved when WPMM is used to match $Z_{e}-R$ pairs compared to those based on TMM and PMM. However, PMM and WPMM do not consider the joint probability between $Z_{e}$ and $R$. From the comparison among the four $Z_{e}-R$ pair matching techniques, it can be concluded that the $Z_{e}-R$ relationship obtained from WCMM provides better estimates of point rainfall and mean areal rainfall than TMM, PMM and WPMM.

Further, the development of WCMM attempts to represent the real physical process of rainfall as the raindrops rarely fall absolutely vertically due to wind effects and also radar measurements are taken at a height much higher than the ground so raindrops take time to reach to the ground. However, this matching technique does not take into account the error of variation of measured reflectivity in vertical profile which is a further area of research. WCMM is therefore a promising method for improved real time radar-measured rainfall input for hydrological and environmental modeling in watersheds, especially those lacking rain gauge data or completely ungauged.

Acknowledgements. This article is a part of doctoral research conducted by the first author at Water Engineering and Management, Asian Institute of Technology, Pathumthani, Thailand. The financial support by the Royal Thai Government for doctoral study is gratefully acknowledged. The authors would like to express sincere gratitude to the staff of 7th Watershed Management Center of the Royal Forestry Department, the Bureau of the Royal Rainmaking and Agricultural Aviation and the Royal Irrigation Department of the Royal Thai Government who assisted and provided rainfall, radar and runoff data for the study area respectively. Thanks are also extended to the staff of the Thai Metrological Department for useful suggestions during the work.

Edited by: J. D. Kalma

\section{References}

Atlas, D.: Advances in radar meteorology, in: Advances in Geophysics, edited by: Atlas, D., Academic press, New York, USA, 318-478, 1964.

Atlas, D., Rosenfeld, D., and Jameson, M. R.: Evolution of radar rainfall measurements: steps and mis-steps, Weather Radar Technology for Water Resources Management, IRTCUD/University of Sao Paulo, Brazil and IHP-UNESCO, 1997.

Atlas, D., Rosenfeld, D., and Wolff, D. B.: Climatologically tuned reflectivity-rain rate relations and links to area-time integrals, J. Appl. Meteorol., 29, 1120-1135, 1990.

Battan, L. J.: Radar observation of the atmosphere, University of Chicago press, Chicago \& London, England, 1973. 
Bell, V. A. and Moore, R. J.: A grid-based distributed flood forecasting model for use with weather radar data: Part 2. Case studies, Hydrol. Earth Syst. Sci., 2, 283-298, 1998, http://www.hydrol-earth-syst-sci.net/2/283/1998/.

Borga, M.: Accuracy of radar rainfall estimates for streamflow simulation, J. Hydrol., 267, 26-39, 2002.

Calheiros, R. V. and Zawadzki, I.: Reflectivity rain-rate relationships for radar hydrology in Brazil, J. Clim. Appl. Meteorol., 26, 118-132, 1987.

Chumchean, S.: Improved estimation of radar rainfall for use in hydrological modeling, Doctoral Dissertation, University of New South Wales, Sydney, Australia, 2004.

Collier, C. G.: Applications of weather radar systems: A guide to uses of radar data in meteorology and hydrology, John Wiley \& Sons, New York, USA, 1996.

Collinge, V. K. and Kirby, C.: Weather radar and flood forecasting, John Wiley \& Sons, Great Britain, England, 1987.

Dairaku, K., Emori, S., Oki, T., and Musiak, K.: Orographic rainfall in tropical mountainous region, the Mae Chaem Watershed, Proc., 2002 workshop on GAME-Topics and hydrometeorological studies in Thailand and Southeast Asia, Chiang Rai, Thailand, 2002.

Joss, J., Schran, K., Thoms, J. C., and Waldvogel, A.: On the quantitative determination of precipitation by radar, Wissenschaftliche Mitteilung No.63, Eidgenossischen Kommission Zum Studium der Hagelgilbung und der Hergelsher, 1970.

Krajewski, W. F. and Smith, J. A.: On the estimation of climatological Z-R relationships, J. Appl. Meteorol, 30, 1436-1445, 1991.
Kuraji, K., Punyatrong, K., and Sirisiyard, I.: Six years intensive rainfall observation in Mae Chaem Watershed, Northern Thailand, The 6th international study conference on GEWEX in Asia and GAME, Kyoto, Japan, 2004.

Kuraji, K., Suzuki, M., Tangtham, N., Jirasuktaveekul, W., and Punyatrong, K.: Observation of rainfall distribution in Mae Chaem Watershed, Proc., the '98 Workshop on GAME-Tropics in Thailand, GAME Publication 7, 24, 1998.

Linsley, R. K., Kohler M. A., and Paulhus, J. L. H.: Hydrology for engineers, McGraw-Hill, London, UK, 1988.

Marshall, J. S. and Palmer, W. Mc.: The distribution of raindrops with size, J. Meteorol. 5, 165-166, 1948.

Rosenfeld, D., Atlas, D., and Short, D.: The estimation of convective rainfall by area integrals, 2: The height area rainfall threshold (HART) method, J. Geophys Res. 35, 2161-2176, 1990.

Rosenfeld, D., Wolff, D. B., and Amitai, E.: The window probability matching method for rainfall measurements with radar, J. Appl. Meteorol., 33, 682-693, 1994.

Rosenfeld, D., Wolff, D. B., and Atlas, D.: General probabilitymatched relations between radar reflectivity and rain rate, J. Appl. Meteorol., 32, 50-72, 1993.

Sun, X., Mein, R. G., Keenan, T. D., and Elliott, J. F.: Flood estimation using radar and raingauge Rata, J. Hydrol., 239, 4-18, 2000.

Vieux, B. E.: Combined use of radar and gauge measurements for flood forecasting using a physics-based distributed hydrologic model, Vieux \& Associates, Inc., Norman, Oklahoma, USA, 2003. 